www.jmscr.igmpublication.org

Impact Factor 5.84

Index Copernicus Value: 83.27

ISSN (e)-2347-176x ISSN (p) 2455-0450

crossref DOI: _https://dx.doi.org/10.18535/jmscr/v5i7.225

Journal Of Medical Science And Clinical Research

\title{
Evaluation of anxiety, depression and suicidal ideation among dermatology patients with cosmetic concerns: A pilot cross sectional study in India
} Authors \section{Masarat Jabeen ${ }^{1}$, Reeta Sood ${ }^{2}$, Manmeet Singh ${ }^{3}$, Shveta Lukhmana ${ }^{4}$, Deepika Sodhi ${ }^{5}$}

${ }^{1}$ Senior Resident, Department of Dermatology, venereology \& leprosy, Acharya Shri Chander College of

Medical Sciences, Jammu (J\&K)

${ }^{2}$ Associate Professor, Department of Dermatology, venereology \& leprosy, Acharya Shri Chander College of Medical Sciences, Jammu (J\&K)

${ }^{3}$ Assistant Professor, Dept of Psychiatry, Acharya Shri Chander College of Medical Sciences, Jammu (J\&K)

${ }^{4}$ Assistant Professor, Department of Preventive and Social Medicine, ESIC Medical College, Faridabad

${ }^{5}$ Intern, Department of Dermatology, venereology \& leprosy Acharya Shri Chander College of Medical sciences, Jammu (J\&K)

Corresponding Author

Manmeet Singh

Department of Psychiatry, Acharya Shri Chander College of Medical Sciences, Jammu (J\&K)

Email:dr.manmeet1222@gmail.com

\begin{abstract}
Background: Cosmetic concerns can negatively affect a person's psychological well being. There is paucity of literature about psychological morbidity in Indian dermatological patients especially those with cosmetic concerns

Methods: This cross-sectional study with consecutive sampling $(n=299)$ was done in the Department of Dermatology at an Indian hospital to find out the prevalence of psychological disorders in patients with cosmetic concerns. Patients were evaluated on validated performas namely 9 item Patient Health Questionnaire (PHQ-9) and 7 -item Generalized Anxiety Disorder Questionnaire (GAD-7), used commonly to assess the presence of psychiatric symptoms in patients.

Results: The patients age ranged between 16-67 years with mean age of $25.76 \pm 16.6$ years (mean \pm 2S.D). More than half of the participants were females (63.5) \%. Majority of patients (90.3\%) belonged to urban areas. The commonest diagnosis were pigmentary disorders $(25.8 \%)$ including melasma, tanning, ephelids, post inflammatory hyperpigmentation followed by acne (23.4) \% and scars (11.7\%). Prevalence rates of depression and anxiety were $38.5 \%$ and $40.1 \%$ respectively. Female patients and office goers were more likely to suffer from anxiety and depression, respectively.

Conclusions: Emotional and psychological assessment is important in dermatology patients with cosmetic concerns. Psychiatric illnesses often go unaddressed in dermatological patients. This lacuna should be taken care of by implementing specific training programmes for dermatologists and developing rational consultation-liaison services with mental health services.
\end{abstract}

\section{Introduction}

In 2017 the theme of world health organization (WHO) year-long focus is on mental illnesses across the world. Studies reveal that there is a high prevalence of psychological disturbances in dermatological outpatients. Unrecognized and 
untreated psychiatric co-morbidity can ruin the quality of life and may turn into fatal suicidal tendencies.

The psychological effect of cosmetic concerns on patients can include embarrassment, frustration, low self-esteem, dissatisfaction with appearance, difficulty in social interactions with the opposite gender, shyness in appearances in public and reduced employment opportunities. ${ }^{1,2}$

Psychodermatology is an emerging arena in dermatology which deals with its interface with psychiatry. How a patient reacts to a dermatological or cosmetic concern can be an interesting and complex interaction between the dermatological lesion, internal factors such as patients' attitude or personality traits and external factors such as social stigma or life stressors. Psychological distress can impair quality of life and vice versa. Perceived disfigurement and associated distress can cause sleep deprivation leading to fatigue, mood lability impaired functioning and suicide in extereme cases. ${ }^{3} \mathrm{~A}$ holistic bio-psychosocial approach is essential in offering comprehensive management of these dermatological concerns. Reassurance, guided counseling and timely referrals are the need of hour in allaying anxiety and psychological distress.

\section{Aims \& Objectives}

To determine the prevalence of depression, anxiety and suicidal ideation among cosmetology patients in a private tertiary care hospital.

\section{Materials and Methods}

This cross-sectional survey was conducted among 299 outpatients visiting dermatology outpatient department for cosmetic concerns at a private tertiary care referral hospital in North India.

Only adults (> 18 years) were included. Those who could not understand English or Hindi were excluded. The profile of patients included patients with cosmetic concerns varying from presence of acne, pigmentation, wrinkles and scar on visible parts of body etc. Ethical clearance was obtained from the Institutional Review Board of the hospital. Confidentiality was maintained at all levels of the study. Demographic and clinical data (including age, gender, education level, employment status, physical activity level, family support, dermatological diagnosis and its duration) was collected from all participants. Depression and anxiety were self-assessed by participants using a 9-item Patient Health Questionnaire (PHQ-9) and 7 -item Generalized Anxiety Disorder Questionnaire (GAD-7), respectively.

These questionnaires were available in two languages: English and Hindi for English and Hindi knowing patients respectively. Each item had four possible responses (never, sometimes, often and almost always) represented by scores of $0,1,2$ and 3 , respectively. The total score ranges from 0 to 21 for GAD -7 and 0-27 for PHQ-9. Both PHQ-9 and GAD -7 are easy to use validated instruments commonly employed to increase identification of patients with substantial psychological distress. $^{4,5}$

The subjects who had a psychiatric diagnosis were referred to the psychiatric and counseling services depending upon the severity of symptoms.

Data were analysed using the Statistical Package for the Social Sciences (SPSS), Version 22 (IBM Corp., Chicago, Illinois, USA). Descriptive analysis was done for demographic and clinical characteristics. Prevalence rates of depression, anxiety and suicidal ideation were reported with 95\% CIs. A Chi-squared test was used to analyse associations between categorical variables and negative emotional states. A $P$ value of $\leq 0.050$ was considered statistically significant and indicated an association through a bivariate analysis. A multivariate logistic regression model was used to study the associations between clinical or sociodemographic variables and psychological morbidity. Adjusted odds ratios (aORs) were used to measure the strength of the associations between risk factors and negative emotional states. 


\section{Results and Discussion}

Fig 1: Association between gender and anxiety

Percentage (\%)

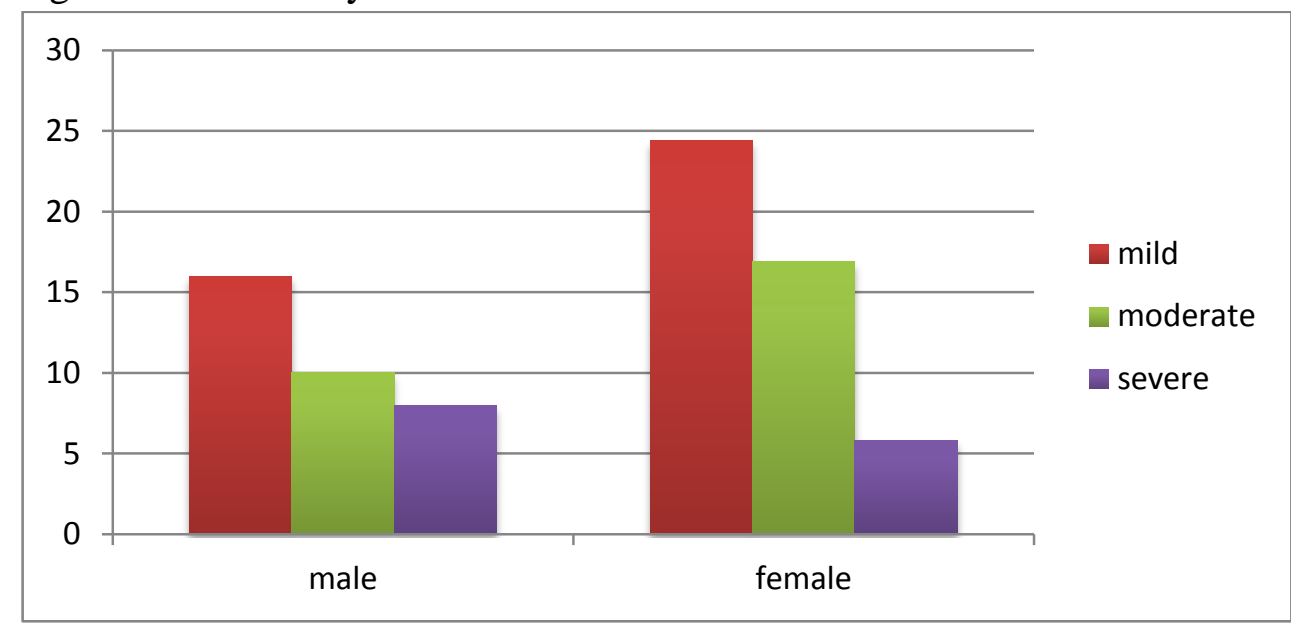

Table 1: Association between gender and psychiatric morbidity

\begin{tabular}{|c|c|c|c|c|c|c|}
\hline \multirow{2}{*}{$\begin{array}{l}\text { Dependent } \\
\text { variable }\end{array}$} & \multirow[t]{2}{*}{ Gender } & \multirow[t]{2}{*}{ Mean \pm S.D. } & \multirow[t]{2}{*}{ T statistic } & \multicolumn{2}{|c|}{ Confidence interval } & \multirow[t]{2}{*}{$\mathrm{P}$ value } \\
\hline & & & & Lower limit & Upper limit & \\
\hline \multirow[t]{2}{*}{ Depression } & Male & $0.43 \pm 0.498$ & \multirow[t]{2}{*}{-0.282} & \multirow[t]{2}{*}{-0.141} & \multirow[t]{2}{*}{0.106} & \multirow[t]{2}{*}{0.778} \\
\hline & Female & $0.45 \pm 0.499$ & & & & \\
\hline \multirow[t]{2}{*}{ Anxiety } & Male & $0.34 \pm 0.476$ & \multirow[t]{2}{*}{-2.146} & \multirow[t]{2}{*}{-0.251} & \multirow[t]{2}{*}{-0.11} & \multirow[t]{2}{*}{0.033} \\
\hline & Female & $0.47 \pm 0.501$ & & & & \\
\hline \multirow{2}{*}{$\begin{array}{l}\text { Suicidal } \\
\text { ideation }\end{array}$} & Male & $0.21 \pm 0.409$ & \multirow[t]{2}{*}{-0.210} & \multirow[t]{2}{*}{-0.113} & \multirow[t]{2}{*}{0.091} & \multirow[t]{2}{*}{0.834} \\
\hline & Female & $0.22 \pm 0.416$ & & & & \\
\hline
\end{tabular}

Table 2: Association between socio-demographic and disease related variables and psychiatric morbidity

\begin{tabular}{|c|c|c|c|c|c|c|}
\hline \multicolumn{2}{|c|}{ Independent variable } & \multirow{2}{*}{$\begin{array}{c}\text { Overall (n) } \\
109 \\
\end{array}$} & \multirow{2}{*}{$\begin{array}{c}\text { Depression } \\
\text { Present }[\mathrm{n}(\%)]\end{array}$} & \multirow{2}{*}{$\begin{array}{c}\mathrm{p} \text { value } \\
0.777 \\
\end{array}$} & \multirow{2}{*}{$\begin{array}{c}\text { Anxiety } \\
\text { Present }[\mathrm{n}(\%)]\end{array}$} & \multirow{2}{*}{$\begin{array}{r}\mathrm{p} \text { value } \\
\mathbf{0 . 0 3 5}\end{array}$} \\
\hline Gender & Male & & & & & \\
\hline & Female & 190 & $77(40.5)$ & & $81(47.1)$ & \\
\hline \multirow{4}{*}{$\begin{array}{l}\text { Age (in } \\
\text { years) }\end{array}$} & $\leq 20$ & 44 & $22(50)$ & 0.594 & $18(40.9)$ & \multirow[t]{4}{*}{0.689} \\
\hline & $21-30$ & 203 & $89(43.8)$ & & $89(43.8)$ & \\
\hline & $31-40$ & 11 & $3(27.3)$ & & $4(36.4)$ & \\
\hline & $\geq 41$ & 14 & $6(42.9))$ & & $4(28.6)$ & \\
\hline \multirow{2}{*}{$\begin{array}{l}\text { Residential } \\
\text { status }\end{array}$} & Urban & 243 & $107(44)$ & 0.935 & $99(40.7)$ & \multirow[t]{2}{*}{0.137} \\
\hline & Rural & 29 & $13(44.8)$ & & $16(55.2)$ & \\
\hline \multirow{5}{*}{$\begin{array}{l}\text { Education } \\
\text { status* }\end{array}$} & Illiterate & 1 & $1(100)$ & 0.406 & $1(100)$ & \multirow[t]{5}{*}{0.718} \\
\hline & Middle school & 2 & $1(50)$ & & $1(50)$ & \\
\hline & Higher secondary & 11 & $3(27.3)$ & & $3(27.3)$ & \\
\hline & Graduate & 237 & $108(45.6)$ & & $101(42.6)$ & \\
\hline & Post graduate & 21 & $7(33.3)$ & & $9(42.9)$ & \\
\hline \multirow{4}{*}{$\begin{array}{l}\text { Occupation } \\
*\end{array}$} & Employed & 102 & $39(38.2)$ & 0.027 & $39(38.2)$ & \multirow[t]{4}{*}{0.297} \\
\hline & Unemployed & 3 & $1(33.3)$ & & $1(33.3)$ & \\
\hline & Student & 162 & $75(46.3)$ & & $71(43.8)$ & \\
\hline & Homemaker & 5 & $5(! 00)$ & & $4(80)$ & \\
\hline \multirow{2}{*}{$\begin{array}{l}\text { Physical } \\
\text { activity }\end{array}$} & Present & 150 & $68(45.3)$ & 0.654 & $62(41.3)$ & \multirow[t]{2}{*}{0.726} \\
\hline & Absent & 122 & $52(42.6)$ & & $53(43.4)$ & \\
\hline \multirow{2}{*}{$\begin{array}{l}\text { Family } \\
\text { support }\end{array}$} & Present & 231 & $106(45.9)$ & 0.163 & $101(43.7)$ & \multirow[t]{2}{*}{0.253} \\
\hline & Absent & 41 & $14(34.1)$ & & $14(34.1)$ & \\
\hline \multirow{3}{*}{$\begin{array}{l}\text { Duration of } \\
\text { disease }\end{array}$} & $<1$ month & 22 & $9(40.9)$ & 0.192 & $12(54.5)$ & \multirow[t]{3}{*}{0.360} \\
\hline & 1-6 months & 95 & $49(51.6)$ & & $42(44.2)$ & \\
\hline & $>6$ months & 155 & $62(40)$ & & $61(39.4)$ & \\
\hline \multirow{2}{*}{$\begin{array}{l}\text { Suicidal } \\
\text { ideation }\end{array}$} & Present & 59 & $48(81.4)$ & 0.000 & $46(78)$ & \multirow[t]{2}{*}{0.000} \\
\hline & Absent & 213 & $72(33.8)$ & & $69(32.4)$ & \\
\hline
\end{tabular}

(*) Fischer exact test 
Table 3: Bar tables showing association between gender and anxiety

Percentage of total patients with anxiety $(\%)$

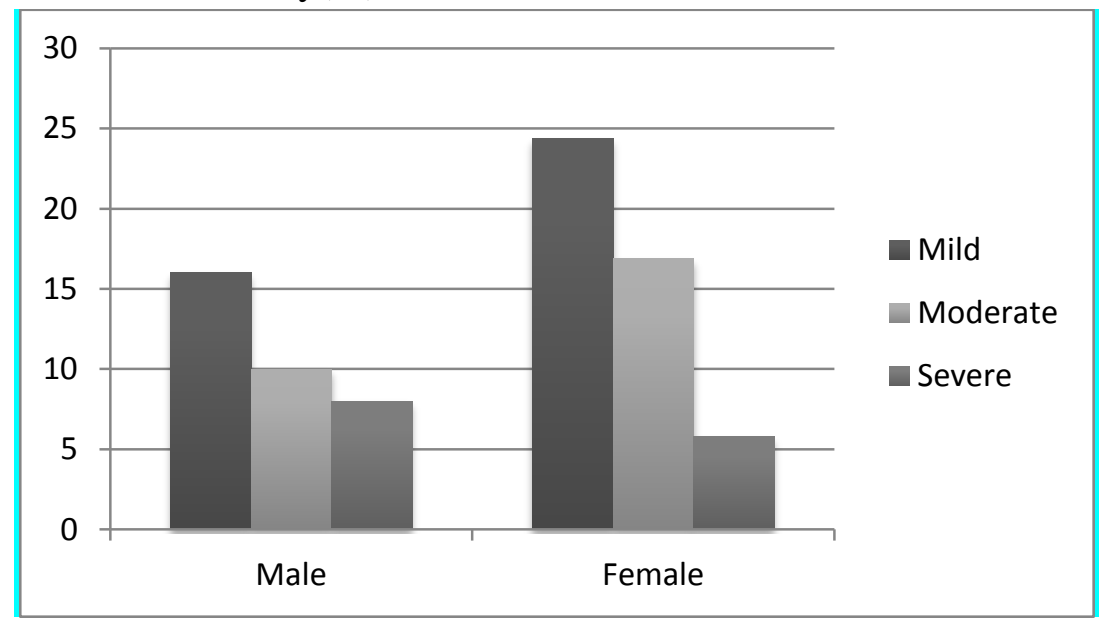

In total, 299 patients were administered questionnaires by the attending physicians. 27 participants returned the performa blank or partially filled (response rate $91 \%$ ). The patients age ranged between 16-67 years with mean age of $25.76 \pm 16.6$ years (mean \pm 2 S.D.) $.14 .7 \%$ of the study population comprised of teenagers while majority of the patients $(70.9 \%)$ belonged to age group 21-30 years. More than half of the participants were females (63.5) \%. Majority of patients $(90.3 \%)$ belonged to urban areas. Most of the patients were educated with 95.3 percent having a college degree. Almost half of the patients had duration of illness more than 6 months.

The commonest diagnosis were pigmentary disorders $(25.8 \%) \quad$ including melasma ,tanning, ephelids, post inflammatory hyperpigmentation followed by acne ( 23.4$) \%$ and scars $(11.7 \%$ ) . Rest of the cosmetic complaints were cateogrised under miscelleneous (facial vitiligo, verruca plana, milia etc.)

$38.5 \%$ patients were diagnosed to have clinically significant depression. It included mild (18.4\%), moderate $(14 \%)$ and severe depression $(7.7 \%)$. The main depressive symptoms were: sadness in mood, fatigue, loss of energy, sleeplessness or excessive sleepiness, guilt and uselessness. $40.1 \%$ patients were found to have clinically significant anxiety. Excessive worrying, restlessness, insomnia, wakefulness after little sleep, irritability and difficulty in concentration were the principal symptoms reported by patients with an anxiety diagnosis. Symptoms of severe anxiety were reported by $6.1 \%$ of patients while $19.4 \%$ and 13 $\%$ of patients had mild and moderate anxiety respectively. Suicidal ideation i.e. thoughts of being better off dead or doing self harm was seen in $21.7 \%$ of patients. Such high prevalence of psychological morbidity could be attributed to negative impact caused by the cosmetic concerns on functionality and quality of life as they are usually on visible parts of body and influence selfperception and social relations.

There was significant female preponderance seen in patients suffering from anxiety (Figure 1). 47.1 $\%$ female patients had anxiety as compared to the male counterparts (34\%). This difference was found to be statistically significant $(\mathrm{p}=0.03)$. (Table 1) Although teenagers had higher rates of anxiety $(40.8 \%)$ than adults aged more than 40 years $(28.6 \%)$, it was not statistically significant. $(\mathrm{P}=0.68)$. The prevalence rate of depression was significantly more common in office goers in comparison to unemployed patients. (38.2\% versus $33.3 \%, \mathrm{p}=0.027)$. It could be corroborated with the fact that office goers are more likely to have social interactions at workplace as well as in commute and hence are more at risk of embarrassment or negative thoughts about their looks. In univariate analysis, the presence of suicidal ideation was significantly associated with higher GAD7 scores. Odds of having anxiety among those who suffered from suicidal ideation were 7.9 times higher than those 
who did not suffer from suicidal ideation. [Adjusted OR: 7.953 (3.953 - 16.001); $\mathrm{p}=0.000$ ]. No other significant association was found between any psychiatric morbidity and other demographic or clinical characteristics. (Table 2) Our data corroborated with other similar surveys which reported significant association of dermatologic disorders with anxiety, depression and suicidal ideations. Psychological factors has been reported in $10-78 \%$ of dermatology patients. $6,7,8,9,10,11,12,13,14,15$

A survey of hospitalized dermatology patients found 45.3 percent of the subjects with depressive symptoms, and 52 percent with symptoms of anxiety. ${ }^{6}$ Anxiety as co morbid feature was prevalent among $57 \%$ of Arab vitiligo patients. ${ }^{16}$ An European multicentric study reported prevalence of depression and anxiety as $10.1 \%$ and $17.2 \%$ in dermatology patients, respectively. ${ }^{17}$ One possible reason for differences in prevalence rates may be the use of different assessment tools having different sensitivities and specificity. Psychological assessment tools used could be physician administered or self reported (by patient) .Our study employed patient reported performa PHQ-9 and GAD-7 with high sensitivity and specificity. The fact that we studied cosmetology patients could also account for high psychological morbidity as cosmetic concerns can lead to self -derogatory feelings, embarrassment and social isolation. ${ }^{1}$

Majority of the patients in the current study had a college degree and belonged to urban areas. This indicates that higher the education and awareness, more is the concern regarding physical appearance leading to medical consultation. Anxiety was found to be higher among females as compared to males. (Table 3) Females were 1.9 times more at risk of having anxiety than males (Adjusted OR $=1.920 ; 1.093-3.37$ ). Higher prevalence of anxiety in females could be due to the fact that women usually are more concerned than men regarding their physical appearance. Especially in Indian culture, societal pressure is more on women to look good as physical unattractiveness in women is considered an obstacle to secure life partner.
Another reason could be that males tend to hide their emotions thinking they would be considered weak by expressing their true feelings.

Similar gender differences in prevalence of psychological morbidity were observed in a Saudi Arabian study. However a study from Norway reported depression to be more common in men than women in dermatitis patients. ${ }^{13,17}$ Socio cultural differences could be the probable explanation behind the gender differences.

Suicidal ideation was reported by significant proportion of subjects $(21 \%)$ in our study similar to other studies. $18.6 \%$, patients suffering from atopic dermatitis reported suicidal ideation in a study from Japan while a Finnish study reported suicidal ideation in $14.5 \%$ of acne patients. ${ }^{18,19}$ The strength of our study is high rate of participation (response rate $91 \%$ ) and the use of pre -validated instruments to diagnose anxiety and depression. The limitations of the study included absence of a control group and non evaluation of personality traits or any concomitant stressful life event. Also, the cross-sectional design of the study does not allow interpretation of the causality of the associations. As no extensive studies have been conducted so far comparing psychiatric comorbidity among all these dermatological diagnoses therefore it was difficult to compare all the conditions included in the present study.

\section{Conclusions}

Our study addresses a common scenario that is actually faced by dermatologists and cosmetic surgeons in their everyday practice, where they are in a unique position to recognize psychiatric morbidity and to take appropriate measures. A high prevalence rate of psychological morbidity especially in female patients stresses the importance of screening for psychological symptoms and suicidal ideation in patients with cosmetic concerns. Although limitations inherent in self-report psychiatric assessment should be considered, the present study suggests that psychiatric illnesses often go unaddressed in dermatological patients. This lacuna should be taken care of by implementing specific training 
programmes for dermatologists and developing rational consultation-liaison services with mental health services.

\section{References}

1. Osman OT, Mufaddel A, Almugaddam F et al. The psychiatric aspects of skin disorders. Expert Rev Dermatol. 2011; 6:195-209

2. Gupta MA, Gupta AK. Psychiatric and psychological co morbidity in patients with dermatologic disorders: Epidemiology and management. Am J Clin Dermatol 2003; 4:833-42

3. Koo J, Lebwohl A. Psycho dermatology: The mind and skin connection. Am Fam Physician 2001; 64:1873-8.

4. Spitzer RL, Kroenke K, Williams JB et al. A brief measure for assessing generalized anxiety disorder: The GAD-7. Arch Intern Med 2006; 166:1092-7

5. Kroenke K, Spitzer RL, Williams JB. The PHQ-9: Validity of a brief depression severity measure. J Gen Intern Med 2001; 16:606-13

6. Gascón MR, Ribeiro CM, Bueno LM et al. Prevalence of depression and anxiety disorders in hospitalized patients at the dermatology clinical ward of a university hospital. An Bras Dermatol. 2012; 87(3):403-7.

7. Chamoun A, Goudetsidis L, Poot $F$ et al.Psoriasis and depression. Rev Med Brux. 2015; 36(1):23-8

8. Lakshmy S, Balasundaram S, Sarkar S et al. A cross-sectional study of prevalence and implications of depression and anxiety in psoriasis. Indian J Psychol Med. 2015; 37(4):434-40

9. Dieris-Hirche J, Gieler U, Kupfer JP et al. Suicidal ideation, anxiety and depression in adult patients with atopic dermatitis. Hautarzt. 2009; 60:641-6.

10. Linnet J, Jemec GB. An assessment of anxiety and dermatology life quality in patients with atopic dermatitis. $\mathrm{Br} \quad \mathrm{J}$ Dermatol. 1999; 140:268-72

11. Golpour M, Hosseini SH, Khademloo M et al. Depression and anxiety disorders among patients with psoriasis: A hospitalbased case-control study. Dermatol Res Pract. 2012; 2012:381905.

12. Mufaddel A, Abdelgani AE. Psychiatric co morbidity in patients with psoriasis, vitiligo, acne, eczema and group of patients with miscellaneous dermatological diagnoses. Open J Psychiatr. 2014; 4:16875.

13. Al Shahwan MA. The prevalence of anxiety and depression in Arab dermatology patients. J Cutan Med Surg. 2015; 19:297-303.

14. Balieva F, Lien L, Kupfer J et al .Are common skin diseases among Norwegian dermatological outpatients associated with psychological problems compared with controls? An observational study. Acta Derm Venereol. 2016; 96:227-31

15. Dalgard FJ, Gieler U, Tomas-Aragones L et al. The psychological burden of skin diseases: A cross-sectional multicenter study among dermatological out-patients in 13 European countries. J Invest Dermatol. 2015; 135:984-91

16. Al-Harbi M. Prevalence of depression in vitiligo patients. Skinmed. 2013; 11:32730

17. Klokk M, Gotestam KG, Mykletun A. Factors accounting for the association between anxiety and depression, and eczema: The Hordaland health study (HUSK). BMC Dermatol 2010; 10:3.

18. Kimata H. Prevalence of suicidal ideation in patients with atopic dermatitis. Suicide Life Threat Behav 2006; 36:120-4.

19. Rehn LM, Meririnne E, Höök-Nikanne J et al. Depressive symptoms, suicidal ideation and acne: a study of male Finnish conscripts. J Eur Acad Dermatol Venereol. 2008; 22(5):561-7. 